\title{
Azeredo Coutinho e a física do voo controlado de balões
}

\author{
Azeredo Coutinho and the physical principles for steering a balloon
}

\author{
José Carlos Corrêa de Andrades*1@, Adriano Martins Moutinho ${ }^{1}$, José Fernandes Pereira ${ }^{1}$ \\ ${ }^{1}$ Centro Federal de Educação Tecnológica Celso Suckow da Fonseca, Rio de Janeiro, RJ, Brasil
}

Recebido em 05 de Novembro, 2018. Revisado em 22 de Abril, 2019. Aceito em 25 de Abril, 2019.

\begin{abstract}
Este artigo tem por objetivo fazer a análise de um manuscrito elaborado pelo bispo Azeredo Coutinho - fundador, em 1800, do Seminário de Olinda, em Pernambuco -, no qual se preocupa com os princípios físicos necessários para dar direção a um balão. Esse manuscrito, ofertado ao príncipe D. Pedro, foi posteriormente publicado em 1819. O problema da dirigibilidade de balões só foi efetivamente resolvido em 1901, com o voo de Santos Dumont em seu dirigível N. ${ }^{\circ}$, que lhe valeu o Prêmio Deutsch. Desde a exibição da subida aos ares de um balão de ar quente na corte de D. João V, realizada pelo padre Bartolomeu de Gusmão, em 1709, a dirigibilidade de aeróstatos - aeronaves mais leves que o ar - parecia um problema insolúvel. Para subsidiar essa análise, buscando contribuir com a história da física no Brasil, o texto explora o desenvolvimento histórico de alguns conceitos físicos que contribuíram para a aerostação, em um contexto de emergência da ciência moderna em detrimento da física aristotélica. A conclusão revela pressupostos das novas ciências naturais, compatíveis com a física de Newton, presentes no pensamento do bispo.
\end{abstract}

Palavras-chave: bispo Azeredo Coutinho, dirigibilidade de balões, história da física no Brasil, aerostação.

This paper aims to provide analysis of a manuscript prepared by bishop Azeredo Coutinho - founder in 1800 of the Olinda Seminary, in Pernambuco - in which he is concerned about the physical principles for steering a balloon. This manuscript, offered to Prince D. Pedro, was later published in 1819. The problem of the dirigibility of balloons was only effectively solved in 1901, with the flight of Santos Dumont in his dirigible balloon No. 6, which earned him the Deutsch Prize. Since the public exhibition of a hot-air balloon at the court of King João V by priest Bartolomeu de Gusmão, in 1709, aerostats (lighter than air aircrafts) steering seemed to be an insoluble problem. To support this analysis in order to contribute to the history of physics in Brazil, the text explores the historical development of some physical concepts which contributed to the aerostation, in the context of the rising of modern science in detriment of Aristotelian Scholasticism. The conclusion reveals assumptions of the new natural sciences present in the bishop's thinking, which are consistent with Newton's physics.

Keywords: bishop Azeredo Coutinho, dirigibility of balloons, history of physics in Brazil, aerostation.

\section{Introdução}

Neste trabalho analisamos um manuscrito elaborado por José Joaquim da Cunha de Azeredo Coutinho (1742-1821), no qual se preocupa em fornecer os princípios físicos necessários para dar direcionamento ao voo de um balão. Esse bispo foi o responsável pela fundação do Seminário de Olinda, em 1800 [1], e pela elaboração dos estatutos da mesma instituição [2], a qual ficou bastante conhecida na historiografia por ser a mais relevante na introdução do ensino das ciências naturais modernas no Brasil [3-18]. Tanto a proposta de ensino feita para esse Seminário, quanto o manuscrito que nos propomos a analisar são permeados pela conjuntura do Iluminismo luso-brasileiro, em consonância com o projeto de reformas de D. Rodrigo de Souza Coutinho (1745-1812). Porém, o que ocorria na transição entre os séculos XVIII e XIX que veio chamar a atenção do bispo para a questão do voo controlado de balões? Quais os obstáculos à realização de um voo dirigido

*Endereço de correspondência: andrades.jose7@gmail.com de balões? Quais os princípios físicos requeridos para que houvesse a dirigibilidade? O quanto Azeredo Coutinho se aproximou conceitualmente desses princípios? Chegou a ser um tema aplicado ao ensino coetâneo? Procuraremos responder a essas questões percorrendo os caminhos da produção do conhecimento científico que contribuíram para a física do voo controlado.

Como em vários trabalhos historiográficos modernos envolvendo a história da física [19-22], procuramos evitar visões simplistas que distorcem os fatos históricos e buscamos contribuir com a definição de conceitos físicos a partir dos processos pelos quais a ciência se desenvolve, percebendo, assim, que essa produção de conhecimento é complexa, e não resultado de gênios que criam suas ideias fortuitamente. A história é um processo não linear, constituída por fatos interdependentes que formam um continuum em que as experiências do passado e do presente se interligam. A ideia científica não é unidirecional, nem consiste na mera acumulação de novas informações, mas na derrubada e/ou redirecionamento 
de antigas concepções. Isso é bem percebido na história do desenvolvimento dos conceitos físicos necessários para dar direcionamento ao voo de um balão, visto que não foi uma questão ocorrida em um instante determinado, mas sim um processo histórico multissecular e com contribuição plural. Dessa forma, observamos um conjunto de regras e princípios que predominaram em determinado momento histórico, possibilitando certas apreensões em detrimento de outras.

Esperamos que o conteúdo deste trabalho seja apropriado por professores e estudantes na área de física e de ciências afins, contribuindo para a percepção dinâmica da construção do conhecimento, a partir da introdução de abordagens histórico-filosóficas no ensino de ciência e tecnologia na educação.

Para atingir o objetivo almejado, além dos escritos de Azeredo Coutinho, foi necessário ler e analisar produções bibliográficas que tratavam da aerostação na época. Isso permitiu um cruzamento dos estudos do bispo e de outros homens da ciência europeia que pensavam sobre as técnicas aplicadas aos aeróstatos e sobre as ciências físicas.

\section{Azeredo Coutinho e seu manuscrito sobre os balões}

Natural dos Campos dos Goytacazes [23] e oriundo de uma família de senhores de engenho, Azeredo Coutinho (Figura 1) entrou para a Universidade de Coimbra em 1775, onde se formou em Filosofia (1778) e em Direito Canônico (1785) [24], no contexto das reformas pombalinas da instrução pública.

Com influências iluministas, as reformas promovidas pelo Marquês de Pombal (1699-1782), ministro do rei D. José I (1714-1777), procuraram renovar o ensino em Portugal, antagonizando-se à escolástica jesuítica ${ }^{1}$ de cunho tomístico-aristotélico, e propiciaram a introdução do ensino da física experimental no reino luso-brasileiro, mais particularmente no Brasil, com a fundação do Seminário de Olinda. Nesse período, uma visão prática das ciências e das técnicas, de teor utilitarista, foi desenvolvida, e o engajamento de Azeredo Coutinho no problema da navegação aérea revelava a almejada sintonia - estabelecida nos Estatutos da Universidade de Coimbra [25] - com as recentes descobertas das ciências e das técnicas, a fim de aplicá-las ao ensino e, por conseguinte, promover o desenvolvimento do reino.

A chamada "febre dos balões" (1783-1785) foi um dos acontecimentos que bem representaram o Iluminismo em Portugal, dentro do espírito de mobilização, manifestado pelo poder real, pelos membros da nobreza e pelo clero em prol dos desenvolvimentos técnico-científicos, o que estava atrelado a uma adequada formação acadêmica.

\footnotetext{
1 De 1549 (chegada) até 1759 (expulsão), os jesuítas detiveram, praticamente, o monopólio da educação no Brasil.

2 Desenhado por Henrique José da Silva (1772-1834) - pintor português e primeiro diretor da Academia Imperial de Belas Artes do Brasil -, e confeccionado em talho doce por Domingos José de
}

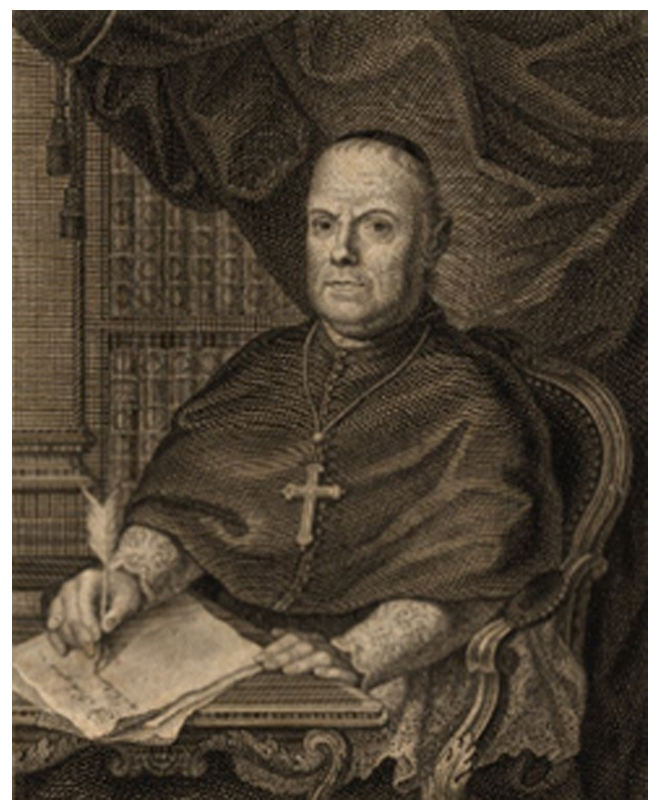

Figura 1: Retrato ${ }^{2}$ do bispo José Joaquim da Cunha de Azeredo Coutinho. (Fonte: Biblioteca Nacional de Portugal)

O manuscrito sobre direcionamento dos balões foi publicado pela primeira vez numa coletânea chamada Coleção de alguns manuscritos curiosos do Exm ${ }^{\circ}$ Bispo de Elva ${ }^{3}$ (Figura 2), em 1819 [26]. A antologia objetivou reunir alguns ensaios de Coutinho, sendo que alguns já haviam sido publicados em dois periódicos portugueses.

Conforme o hábito da época, os autores ofereciam seus textos a algum membro da Família Real. No caso, Azeredo Coutinho dedicou sua obra ao então príncipe D. Pedro (1798-1834), que viria a se tornar D. Pedro I do Brasil.

Em linhas gerais, o texto de Azeredo Coutinho apresenta o formato descrito a seguir, em que as demonstrações são aqui omitidas para posterior análise mais detalhada:

Ao Sereníssimo Sr. D. Pedro, Príncipe do Brasil, dedica-se o seguinte:

\section{Problema}

- Dar-se a direção que se quiser a um balão que boia no fluido da atmosfera -

A resolução deste problema depende da resolução dos teoremas seguintes:

Teorema $1^{\circ}$

- Dar-se um ponto de apoio na corrente do fluido da atmosfera sobre a qual o balão boia.

Demonstração $1^{a}$

$[\ldots]$

\section{Demonstração $2^{a}$}

Ricardo da Silva, em 1816, a pedido do cônego prebendado da Sé de Elvas João Joaquim de Andrade, que também era secretário de Azeredo Coutinho e Cavaleiro da Ordem de Cristo. Esta obra está digitalizada e disponível na Biblioteca Nacional de Portugal (cota E-5012-P)

3 Azeredo Coutinho ocupou o bispado de Pernambuco de 1798 a 1802, sendo então eleito para o bispado de Elvas, em Portugal. 


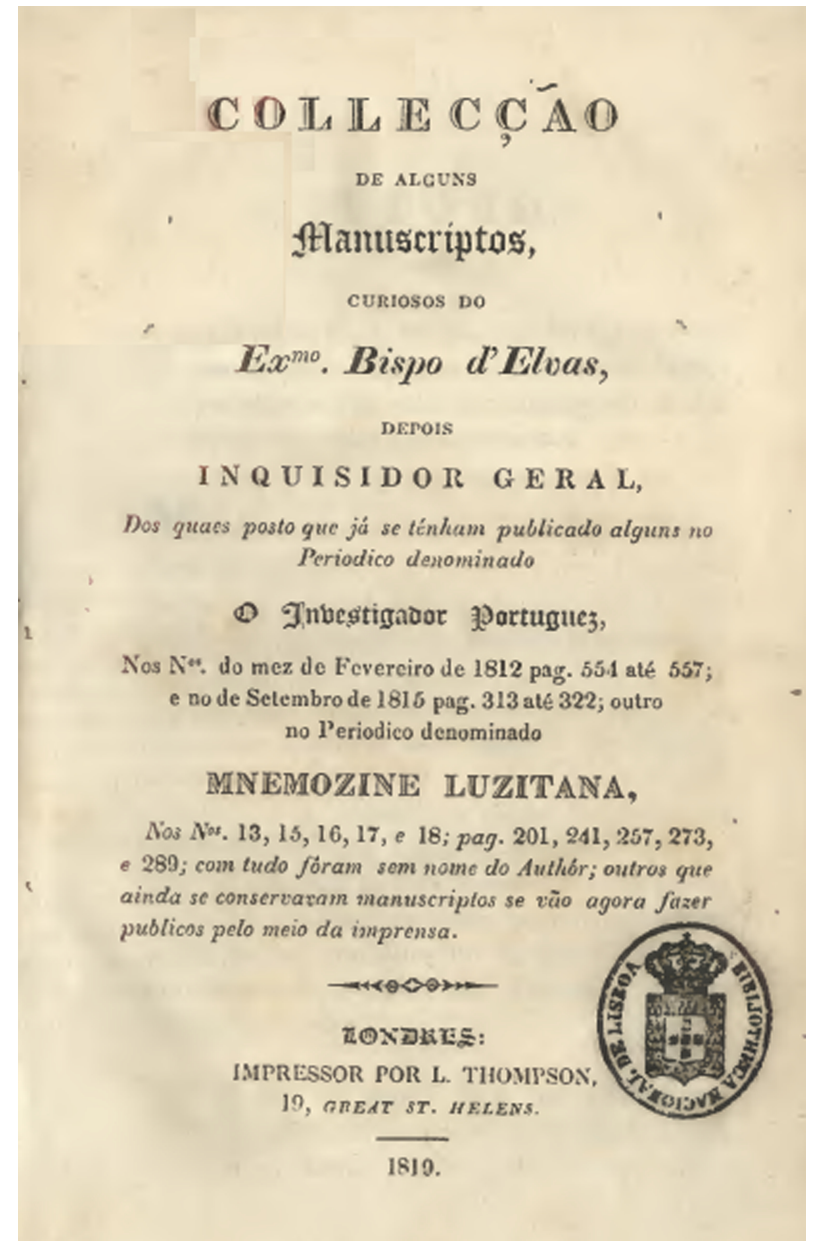

Figura 2: Folha de rosto da obra Coleção de alguns manuscritos curiosos do Exmo Bispo de Elvas, do Arquivo da Biblioteca Nacional do Rio de Janeiro [26]

$$
[\ldots]
$$

\section{Teorema $2^{\circ}$}

- Dar-se uma força impulsiva no balão de uma velocidade maior do que a da corrente do fluido da atmosfera sobre a qual o balão boia.

\section{Demonstração}

[...] [26]

Uma vez apresentado o problema, Coutinho realizou as demonstrações dos dois teoremas - seguindo o método axiomático, como era comum no período -, para mostrar como o problema da navegação aérea poderia ser resolvido.

\section{Conceito e desenvolvimento histórico da aerostação}

Chamam-se aeróstatos as aeronaves que têm a característica de serem mais leves que o ar. Na contemporaneidade, são divididos em duas grandes categorias: balões e dirigíveis. Os balões não dirigíveis dependem da direção do vento para orientar a sua navegação. Como as correntes de ar têm direções que variam em função de sua altitude, esse tipo de balão se utiliza de controles de subida e descida, com a finalidade de aproveitamento do fluxo da corrente de ar em certa altura. Balões assim não conseguem retornar ao ponto de partida, e seu local de pouso é sempre incerto. Já os dirigíveis apresentam propulsão própria e, com formato aerodinâmico adequado, permitem o controle da direção da aeronave, independentemente do vento. A história da aerostação se confunde com os primórdios da aviação, que se dedica ao estudo das aeronaves mais pesadas que o ar. Tais especialidades de estudo, dentro da história das ciências e das técnicas, muito revelam sobre a contribuição de pensadores brasileiros 4 .

Na época de Azeredo Coutinho, a aerostação estava em seu início, tendo como grande evento motivador a apresentação pública do voo de um balão em Annonay, sul da França, em 4 de junho de 1783 [27], realizada pelos irmãos franceses Joseph-Michel Montgolfier (1740-1810) e Jacques-Étienne Montgolfier (1745-1799). A conquista do ar já era um antigo sonho do homem, sonho este que atravessou diferentes culturas. O historiador inglês Noel Joseph T. M. Needham (1900-1995) aponta para a possibilidade de o povo chinês haver sido o precursor dos balões de ar quente, no século II a.C. [28], apesar de o aeróstato ser completamente desconhecido na China quando da divulgação dos balões a partir do experimento de Annonay [29].

Ocorreu, entretanto, mais de sete décadas antes dos ensaios aerostáticos dos Montgolfier, outro evento que merece ser destacado. Tratou-se da exibição realizada pelo padre brasileiro Bartolomeu Lourenço de Gusmã $\complement^{5}$ (1685-1724), que fez um balão de ar quente flutuar em 1709, diante da corte de D. João $\sqrt{6}$ de Portugal.

Só no final do século XVIII a "febre" dos aeróstatos começou a se espalhar por toda a Europa e a América. O balonismo se alinhou ao cunho utilitarista da ciência iluminista, pois a ideia de um balão que possibilitasse o transporte rápido de mensagens, víveres e pessoas possibilidades já imaginadas por Bartolomeu de Gusmão - parecia mais próxima. Foi nesse contexto que quatro alunos de Domenico Vandelli (1735-1816) - professor italiano contratado para ser o primeiro lente de Química e História Natural após as reformas pombalinas -, entusiastas do balonismo, realizaram experimentos aerostáticos na Universidade de Coimbra, o que foi noticiado pela $G a-$

\footnotetext{
4 Utilizamos neste trabalho o termo "brasileiro" para designar as pessoas nascidas no território que na contemporaneidade é entendido como Brasil, visto que no período colonial ainda não existia esse Estado nacional e o termo "brasileiro" foi usado, em vários momentos daquele período, com significados distintos do atual.

5 Seu nome de batismo era apenas Bartolomeu Lourenço. Passou a assinar Bartolomeu Lourenço de Gusmão a partir de 1718, quando aditou ao patronímico paterno o nome de seu padrinho, mestre e protetor, o padre jesuíta Alexandre de Gusmão.

6 O escritor Francisco Freire de Carvalho Figueiredo foi o primeiro a transcrever a "petição de privilégio" (como era chamado o pedido de patente na época) de Bartolomeu de Gusmão, que fora lida na Seção Literária da Academia Real das Ciências de Lisboa de 20 de maio de 1840 [30].
} 
zeta de Lisboa de 17 de julho de 1784 [31]. Esses quatro alunos foram: Tomás José de Miranda e Almeida - alferes do regimento de cavalaria de Elvas -; Salvador Caetano de Carvalho; Vicente Coelho de Seabra; e José Álvares Maciel. Os dois últimos eram brasileiros que se tornariam eminentes no campo da ciência química. A criação de máquinas aerostáticas com vistas ao transporte de pessoas era uma possibilidade recente, que excitava a curiosidade dos ilustrados da Europa, e dentro da proposta da nova Universidade, em sintonia com as novas descobertas, já se praticava a aerostação. Foi nesse ambiente que Azeredo Coutinho se formou e absorveu vários dos ideais iluministas.

\section{A história da física do voo de balões e as primeiras ideias de um voo controlado}

Azeredo Coutinho inicia o seu manuscrito sugerindo o seguinte problema: "Dar-se a direção que se quiser a um balão que boia no fluido da atmosfera" [26, p. 71]. O fundamento físico básico envolvido na ascensão dos balões já era conhecido desde a Antiguidade: tratava-se do empuxo de Arquimedes (287 a.C.-212 a.C.). Segundo esse princípio, todo corpo mergulhado total ou parcialmente em um fluido - como é o caso do balão imerso no ar - recebe uma força de baixo para cima que é igual ao peso do volume do fluido por ele deslocado. Essa força, o empuxo, é o que faz o balão subir, desde que o gás que preenche o balão tenha densidade menor que a do ar. Nisso consiste o princípio fundamental da hidrostática, apresentado no tratado Sobre os corpos flutuantes [32], de Arquimedes.

Conhecimentos como a mecânica e a hidrostática os dois ramos em que Azeredo Coutinho dividia a física experimental - foram valorizados no Seminário de Olinda, reconhecidos como necessários para mover e levantar grandes corpos, e conduzir águas em um país fundamentalmente agrícola [2, p. 62]. Dentro de um espírito fisiocrata 7 a agricultura era valorizada, assim como tudo relacionado a ela, mostrando como o progresso das ciências conduzia a técnicas atualizadas para dar soluções práticas. Tratava-se da representação mais clara da complementaridade entre natureza e civilização, pois era da terra que se extraíam os produtos necessários para a sobrevivência e o lazer do homem. Esses conhecimentos também eram úteis para resolver um problema técnico da época: o direcionamento de balões navegando pelo ar. Esse talvez seja o melhor exemplo do entrosamento de Azeredo Coutinho com a modernidade técnico-científica

\footnotetext{
7 O sucesso do mecanicismo de Newton - com suas leis para a explicação do mundo natural - teve grande influência em várias áreas do conhecimento, inclusive em precursores da economia na França [33], os quais ficaram conhecidos como fisiocratas. A palavra fisiocracia provém do mesmo radical grego - physis - da palavra física e tem o sentido de "governo da natureza", pois esses economistas acreditavam que a economia também podia ser entendida por meio de leis.
}

de sua época, aplicando princípios das ciências físicas modernas na solução de um problema atual, porém inatingível na prática, em razão das limitações tecnológicas do tempo em que o bispo viveu.

Com o modelo criado pela física aristotélica ${ }^{8}$ já era possível dar uma explicação de como uma máquina adequadamente construída poderia ser conduzida pelo ar, do mesmo modo que um barco pode ser transportado pela água, segundo o princípio de Arquimedes. A historiografia costuma atribuir a Alberto da Saxônia (c.1320-1390), bispo de Halberstadt 9 a prioridade dos que desenvolveram uma explicação segundo esse modelo [35 - 41]. Todavia, algumas diferenças significativas podem ser observadas entre o modelo adotado por Alberto e o modelo de explicação da natureza que Azeredo Coutinho usou em sua proposta. Quando Coutinho falava de "atmosfera", já havia a concepção de uma mistura de gases, de um ar que tinha peso e, fundamentalmente, já se admitia a existência do vácuo. Tais propriedades foram sendo reveladas com a experimentação, característica marcante da ciência moderna, embora já fosse valorizada por pensadores anteriores à Revolução Científica.

No pensamento aristotélico, o ar não era uma mistura de gases, como na concepção moderna, mas um elemento fundamental. Segundo essa concepção, que foi retomada de Empédocles no século V a.C., todas as coisas no mundo terrestre - o mundo sublunar - têm a sua origem a partir de uma combinação dos elementos terra, água, ar e fogo [42, p. 33-35]. Um quinto elemento, o éter, comporia o mundo supralunar. Assim, as leis que regiam a mecânica terrestre eram diferentes das leis que regiam a mecânica celeste. A pluralidade dos objetos seria explicada pelas diferentes proporções desses elementos primordiais em sua composição; cada um dos elementos teria um lugar natural, o que gerou a concepção de movimento natural em Aristóteles ${ }^{10}$ A terra e a água, por serem os elementos mais pesados tenderiam a se mover para baixo. Uma pedra, sendo um composto pesado e tendo o elemento terra em maior quantidade na sua composição, tenderia a cair quando fosse abandonada, buscando seu lugar natural. O ar e o fogo, ao contrário, por serem mais leves tenderiam a subir, buscando o seu lugar natural em cima [42, p. 60].

Os textos aristotélicos foram bastante debatidos por estudiosos do século XIV que, segundo modernas interpretações historiográficas, constituíram uma rede intelectual onde havia um compartilhamento de ideias e cuja base organizacional era a Faculdade de Artes de Paris [43]. Fariam parte dessa rede, dentre outros, Jean Buridan

\footnotetext{
8 Para Aristóteles, a física era considerada a "filosofia segunda", enquanto a metafísica era a "filosofia primeira".

9 O bispado de Halberstadt na Baixa Saxônia perdurou de 1180 a 1648, pertencendo ao antigo Sacro Império Romano-Germânico, região pertencente à atual Alemanha. Alberto teria nascido provavelmente em torno de 1320 e não 1316, como é tradicionalmente colocado [34].

$10 \mathrm{O}$ conceito de movimento era mais amplo em Aristóteles, envolvendo outras categorias além da ideia de mudança de posição.
} 
(1300-1358), Nicole Oresme (c.1320-1382) e Alberto da Saxônia. É nesse contexto que nos comentários sobre a obra Física de Aristóteles (constituída por 8 livros), as Quaestiones super octo libros Physicorum ${ }^{11}$ de Alberto que foram passadas em 18 manuscritos e pelo menos 5 edições impressas - estariam respondendo à Tertia Lectura das Quaestiones super octo libros Physicorum de Buridan (passadas em 4 manuscritos), enquanto a $U l$ tima Lectura deste (preservada em 31 manuscritos) seria a resposta a Alberto, de forma que ocorria um debate entre ambos ${ }^{12}[44]$. Era comum que autores reformulassem suas interpretações sobre determinados textos de Aristóteles, criando uma sequência de lecturas. As Quaestiones - que envolviam não só questões (quaestiones) como comentários detalhados (expositio) - representam as obras mais importantes em filosofia natural dos dois mestres. A relação entre elas é complexa e discutida por muitos estudiosos. Benoît Patar, em sua edição crítica intitulada Expositio et quaestiones in Aristotelis Physicam ad Albertum de Saxonia attributae: Édition critique, atesta que o texto tradicionalmente atribuído a Alberto da Saxônia seria, em realidade, a primeira versão do comentário de Buridan [45] e, consequentemente, refere-se à Tertia Lectura como Secunda Lectura de Buridan. Não obstante, Thijssen [44, p. 27-29] e outros estudiosos discordam dessa análise, pois a tese de Patar não é apoiada por evidências textuais ou paleográficas.

É no terceiro e último volume da obra de Patar (Figura 3) que se aborda a questão VI, artigo II, terceira conclusão do Livro IV das questões sobre a Fisica de Aristóteles atribuídas a Alberto da Saxônia. Nessa questão, Alberto explicou que, por ser mais leve que o ar, o fogo busca seu lugar natural: acima do ar (por isso a fumaça sobe). Portanto, se uma pequena quantidade de fogo estivesse enclausurada em uma embarcação, essa embarcação se elevaria no ar, sendo a região contígua ao empíred ${ }^{13}$ navegável, em teoria, como a superfície da água, que também é contígua ao ar [46]. Destarte, a percepção de que o ar quente é mais leve que o ar frio pode facilmente haver ocorrido em vários momentos da história.

Uma obra da época, chamada Recreação Filosófica (Figura 4) - um projeto de condensação enciclopédica de 10 volumes - foi usada como referência para o ensino das novas ciências naturais, tanto na Universidade de Coimbra reformada quanto no Seminário de Olinda [18]. Essa obra foi escrita pelo padre oratoriano Teodoro de

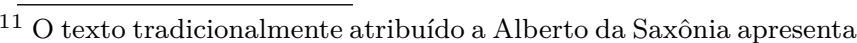
variedades na apresentação do título, como Expositio et quaestiones in Aristotelis Physicam, Quaestiones super libros Physicorum, dentre outros.

12 Essa ideia de rede intelectual - adotada por vários estudiosos, dentre os quais Thijssen e Michael J. Fitzgerald - contrapõe-se à tradicional teoria da existência de uma "Escola de Buridan" defendida por Pierre Duhem, onde Alberto da Saxônia seria aluno de Buridan e um mero reprodutor de suas ideias.

13 Nome dado, em certos sistemas cosmológicos da Antiguidade, à esfera celeste superior, que seria ocupada pelo elemento fogo. $\mathrm{O}$ fogo formaria uma esfera ao redor do fluido ar, segundo Alberto da Saxônia.
}

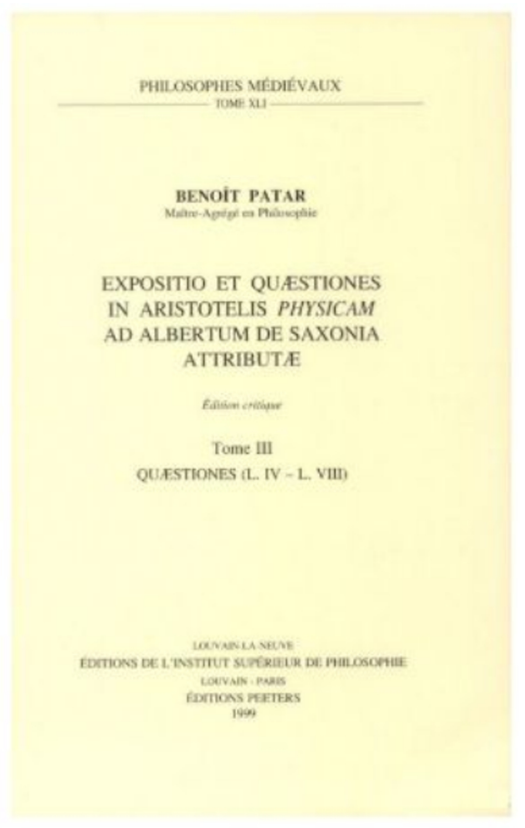

Tertia conclusio quod ignis est multo subtilior et rarior et levior aere. Patet hoc: nam se videtur habere ad aerem sicut aer se habet ad aquam; modo aer est multo rarior, multo subtilior, multo levior quam sit aqua; ergo sic est de igne respectu aeris.

Ex hoc sequitur, et posset diffusius ostendi ex scientia de ponderibus, quod aer supra, ubi est contiguus igni, est navigabilis, sicut aqua, ubi est contigua aeri. Unde, si esset supra aerem aliqua navis, interim quod non repleretur aere sed igne, non submergeretur in aere, sed in igne; sed, quamcito esset repleta aere, submergeretur in aere, sicut in aqua, interim quod navis est repleta aere et non aqua, natat et non submergitur, sed quando est repleta aqua, tunc submergitur. Ita proportionaliter imaginandum est hic et ibi.

Figura 3: Capa e trecho do livro Expositio et quaestiones in Aristotelis Physicam ad Albertum de Saxonia attributae

Almeida (1722-1804) e explicita o que ficou conhecido como a Querela entre antigos e modernos 14 A obra era constituída por diálogos que contrapunham os conceitos de filosofia natural segundo os antigos (escolástica peripatética) e os novos conceitos da filosofia natural dos modernos. Representou uma proposta pedagógica para atingir um vasto público com conhecimentos atualizados, além do que normalmente era aplicado às escolas.

Na Recreação Filosófica se identificavam vários elementos discordantes entre a escolástica e os princípios da ciência moderna, como a admissão da existência do vácuo e de que o ar tem pesq ${ }^{15}$. A teoria dos graves

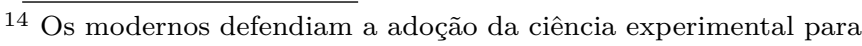
ser adotada pelo sistema de ensino português, enquanto os antigos defendiam a permanência da corrente escolástica tomística.

${ }^{15}$ A constatação de que o ar tinha peso - com os experimentos de Evangelista Torricelli (1608-1647), discípulo de Galileu - conduziu à explicação de que a sucção numa bomba de água tinha a ver com a pressão exercida pelo ar. Houve então uma revisão do conceito de ar, pois o fenômeno de sucção era explicado - na filosofia aristotélica - pelo chamado horror vacui, ou seja, a aversão da natureza ao vácuo [47]. A natureza tenderia a evitar a formação de espaços vazios, o que explicaria por que a água segue o êmbolo de uma bomba. 

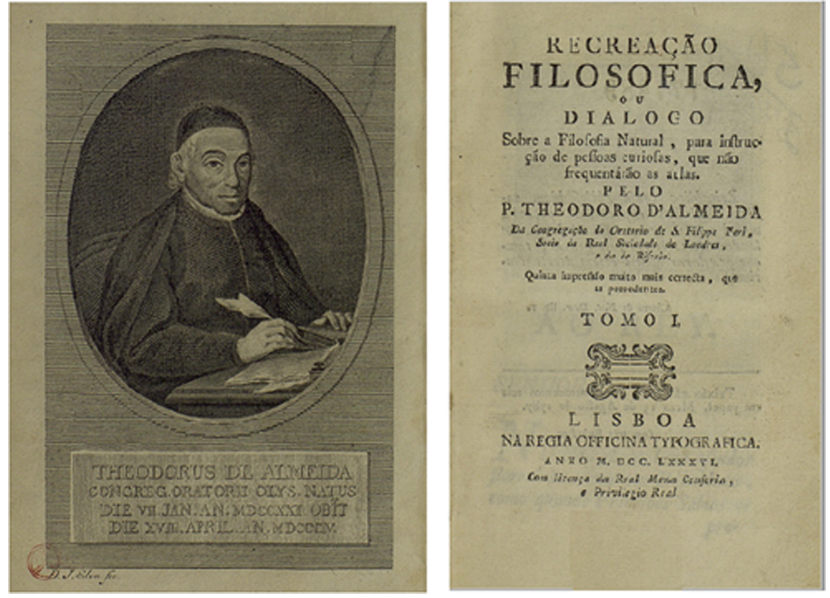

Figura 4: Livro Recreação filosófica do padre oratoriano Teodoro de Almeida [48].

(corpos pesados) e lugares naturais da física aristotélica foi substituída pela filosofia mecanicista de Galileu, Newton e Descartes. Há ênfase nos experimentos, com vários exemplos destes, usando vários tipos de equipamentos, como as máquinas pneumáticas 16

Logo no primeiro volume da Recreação, encontramos a proposta de que uma máquina pneumática (bomba de vácuo) poderia ser usada para retirar o ar de quatro bolas feitas de um metal muito delgado. Dessa forma, as bolas ficariam mais leves que o ar e subiriam, segundo o princípio do empuxo de Arquimedes, levantando um barco que estaria preso a elas. O barco deveria ser construído de material o mais leve possível, e estar equipado com "remos de penas, à maneira de asas"; dessa forma, o sistema poderia ser governado do mesmo modo que um barco tem sua direção controlada na água [48, p. 339-340]. Três pontos importantes podem ser depreendidos dessa proposta:

$1^{\circ}$ ) A descrição do porquê a nave sobe já envolve uma concepção moderna de ar, e não uma explicação por fundamentos aristotélicos;

$2^{\circ}$ ) A ideia da nave voadora remetia a uma das primeiras contribuições à navegação aérea, responsável por influenciar vários projetos posteriores: o projeto do barco voador (Figura 5) do padre jesuíta italiano, matemático e naturalista, Francesco Lana Terzi (1631-1687). Esse projeto foi apresentado em 1670, em seu livro de invenções Prodromo ovvero saggio di invenzioni nuove all'Arte Maestra.

$3^{\circ}$ ) Havia a proposta de dirigir um balão pelo ar, usando-se remos, velas e a força motriz humana. Isso se baseava na suposição ingênua, que perdurou por séculos, de que se poderia obter dirigibilidade em uma navegação no ar por analogia aos princípios da navegação na água.

16 Sete anos depois da descoberta de Torricelli em 1643, o investigador alemão Otto von Guericke (1602-1686) desenvolveu a bomba de vácuo, que se tornou muito útil para vários experimentos em física e inspirou a possibilidade de criar balões flutuantes pela retirada do ar do seu interior.

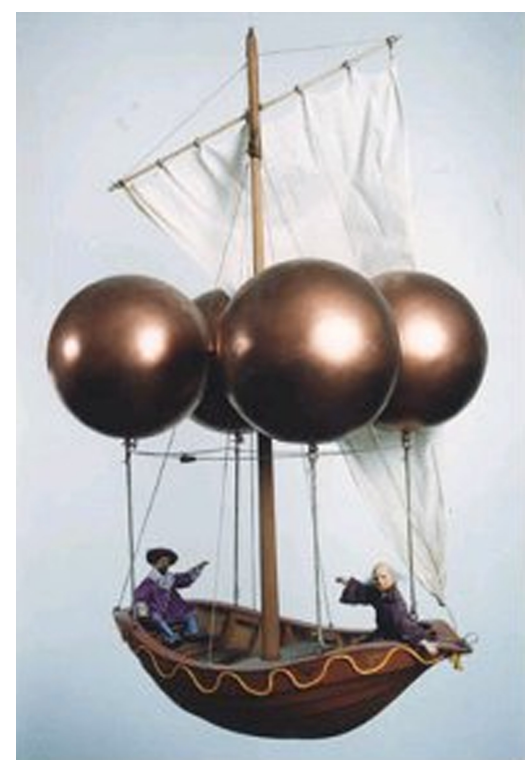

Figura 5: Modelo do projeto do barco voador do padre Francesco Lana. (Fonte: Lilienthal Museum)

O cerne da proposta para a elevação do balão, encontrada no livro de Teodoro de Almeida, é o mesmo da proposta encontrada no projeto do padre Lana. Em ambas é utilizado um sistema constituído de quatro globos de cobre, grandes, finos e vazios. A ideia era fazer os globos subirem retirando-lhes o ar, produzindo um vácuo interno. O motivo do uso de metais leves para os globos era o fato de que uma bexiga murcharia sob a pressão atmosférica, perdendo a sua forma esférica. Porém, Teodoro de Almeida [48, p. 341-342] e, posteriormente, o autor Marion em 1888 [49, p. 13], alertaram para as dificuldades de tal projeto de barco voador. Seria necessário conseguir materiais leves o bastante para flutuar e ainda levantar um homem, e caso se conseguisse um cobre tão delgado quanto se propunha para a confecção dos balões, inevitavelmente estes se colapsariam sob a pressão atmosférica.

As propostas voltavam-se para aplicação do vácuo, pois a bomba de vácuo (máquina pneumática) já fora desenvolvida por Von Guericke. Na época do projeto do padre Lana, em 1670, as propriedades mais leves do ar quente ainda não haviam sido aplicadas de forma efetiva e o gás hidrogênio ainda não era conhecido [49, p. 13]. As primeiras edições dos volumes I e II do projeto Recreação filosófica saíram em 1751, encontrando-se, portanto, distantes no tempo da esquecida apresentação de Bartolomeu de Gusmão (1709), situando-se anteriormente aos experimentos dos irmãos Montgolfier (1783) e à identificação do hidrogênio (1766). Isso talvez explique a proposta do balão ainda utilizando o vácuo. À época de Azeredo Coutinho, entretanto, já haviam ocorrido as experiências aerostáticas com Vandelli, as quais se iniciaram com balões de ar quente - passando posteriormente à utilização do gás hidrogênio - na Universidade de Coimbra. 
Com a identificação do hidrogênio e do oxigênio, a teoria dos quatro elementos para o mundo sublunar de Aristóteles - terra, água, fogo e ar - passou a não mais se adequar, pois começava a ficar evidenciado que o ar não era um dos elementos fundamentais [50, p. 70]. Apesar de a proposta no livro de Teodoro de Almeida já se utilizar da concepção moderna de ar, ainda se baseava no controle de navegação aérea sugerido no modelo do padre Francesco Lana, de 1670, o qual aplicava o pressuposto da navegação na água. Em princípio, não havia outro meio de tentar a dirigibilidade senão usando mecanismos conhecidos da arte náutica: velas, leme ou remos, mas pensados de forma a adaptá-los para o ar [50, p. 74]. Por isso a proposta no livro de Teodoro de Almeida referia-se a "remos de penas, à maneira de asas".

A ideia de conduzir uma embarcação no fluido ar de modo análogo a guiar uma embarcação no fluido água era muito antiga. $\mathrm{O}$ frade franciscano e filósofo inglês Roger Bacon (1214-1294), por exemplo, em sua Epistola de Secretis Operibus Artis et Naturae et de Nullitate Magiae, especulou, em várias passagens, a hipótese de construção de máquinas voadoras e submarinos [51]. Bacon observara que o ar, assim como a água, tinha algumas características próprias dos sólidos, chegando à conclusão de que, com as técnicas adequadas, um artefato poderia voar pelo ar da mesma forma que um navio navegava pelo mar. Marion [49, p. 13-14] explicou o erro de concepção que fora aplicado ao projeto de Lana: o uso de velas para o direcionamento. Isso não daria certo como ocorre numa navegação marítima, e a aeronave ficaria à mercê da direção do vento. Marion explicou que no caso de um barco na água, quando as velas se inflam com o vento, há duas forças em operação: a força ativa do vento e a força passiva da resistência da água. Uma vez atuando uma força contra a outra, o marinheiro pode girar para um ponto em qualquer direção que deseje. Já no caso da flutuação no ar, não há ponto de apoio, e o sistema fica submetido à ação de uma única força, não produzindo o efeito de direcionamento desejado. Será que a proposta de Azeredo Coutinho ainda incorria nesse equívoco?

\section{A solução de Azeredo Coutinho}

A preocupação de Azeredo Coutinho com a navegação aérea refletia a questão persistente desde que o primeiro balão de ar quente subiu aos ares: como dirigi-lo? A questão da dirigibilidade dos aeróstatos era algo que clamava por uma solução e empolgava a mente de vários pensadores do final do século XVIII. Várias tentativas de voo à semelhança da navegação marinha se seguiram logo após os experimentos dos irmãos Montgolfier. Entretanto, há diferenças significativas entre a navegação aérea e a navegação marítima, como Marion [49] explicou. Já em 21 de janeiro de 1784, o conde de Milly tinha apresentado uma memória à Real Academia de Ciências de Paris, justificando essas diferenças. Segundo o que explicava o autor, não há sustentação no meio ar do mesmo modo que no meio água, pois a aeronave fica completamente imersa no fluido ar, cuja densidade é oitocentas vezes menor que a da água. Dessa forma, o uso de velas e remos torna-se inútil [52]. Podemos tentar entender tais princípios a partir do que Azeredo Coutinho expôs em seu manuscrito, e assim verificar se este incorria no mesmo erro ou não.

Em seu texto, Azeredo Coutinho sustentava que a solução do problema da navegação aérea dependeria da resolução de dois teoremas por ele apresentados. Assim, o bispo fez duas demonstrações para o primeiro teorema, e uma demonstração para o segundo. As demonstrações foram feitas usando o método axiomático, popularizado a partir de Euclides (c.325 a.C.-c.265 a.C.) e muito utilizado no período em questão. Foi, também, o método utilizado por Newton em seu Principia [53], onde o cientista escolheu a tradição de Galileu e sintetizou o método indutivo-experimental de Bacon com o sistema axiomático de corte hipotético-dedutivo [54]. O uso de métodos analíticos, com demonstrações algébricas, só se solidificou no decorrer do século XIX.

O método axiomático tem três etapas. A primeira é a formulação de um sistema axiomático, ou conjunto dedutivamente organizado de axiomas, definições e teoremas. Ou seja, é uma etapa em que se escolhem noções e conceitos primitivos. A segunda consiste em especificar um procedimento para correlacionar os teoremas do sistema axiomático com as observações, usando argumentação lógica. Finalmente, a terceira é a confirmação das consequências inferenciais do sistema axiomático empiricamente interpretado. Logo, é a etapa do método na qual se alcançam os resultados a partir da manipulação dos conceitos com a lógica.

O primeiro teorema proposto por Coutinho enuncia: "Dar-se um ponto de apoio na corrente do fluido da atmosfera sobre a qual o balão boia" [26, p. 71]. Para realizar a primeira demonstração relativa a esse teorema, Coutinho parte do fato, então conhecido, de que um corpo que boia sobre a corrente de um fluido qualquer é levado pela corrente desse fluido, sem qualquer direção. Entretanto, quando esse corpo boiante encontra algum apoio ou resistência, muda de direção. Assim, um balão que boia sobre o fluido da corrente da atmosfera poderá mudar de direção se lhe for dado um ponto de apoio ou resistência.

Nesse ponto, já se pode observar a sintonia do bispo com os recentes postulados científico-tecnológicos da época em que viveu e atuou, pois há uma clara distinção entre a navegação na água e a navegação no ar. Tanto um barco sem propulsão própria quanto um balão solto no ar, se abandonados nos respectivos fluidos, serão levados de acordo com a correnteza, sem direção previamente definida, como Azeredo Coutinho expôs em seu primeiro teorema. O que falta para dar o direcionamento é "encontrar algum ponto de apoio". Essa afirmação está de acordo com o que o Conde de Milly [52] afirmara: enquanto um balão está totalmente imerso no meio ar, 
sem qualquer sustento, um barco encontra-se na interface entre dois meios - a água e o ar. Dessa forma, a água fornece uma sustentação que não é proporcionada a uma aeronave, pois esta se encontra completamente imersa no fluido ar. O barco encontrará um ponto de apoio caso um remo seja usado para o seu direcionamento. Seu movimento resultante decorre de uma composição de forças que não existe no balão. Ou seja, a água e o ar têm, em conformidade com o comentário de Milly, densidades diferentes, o que neles produz diferentes valores de resistência ao movimento e, consequentemente, velocidades diferentes que podem gerar uma composição de forças no barco. Por esse motivo, nem velas nem remos resolveriam o problema do direcionamento do balão, pois este estaria submetido à ação de uma única força. Não obstante, aplicando-se outra força em direção diferente à do deslocamento, uma força resultante pode ser obtida a fim de dar um posicionamento preestabelecido pelo navegador. Assim, se for encontrado um modo de obter um ponto de apoio - como Coutinho apresentou em seu primeiro teorema - ou resistência no fluxo de ar, o balão poderá ser direcionado pela ação de um leme adequadamente posicionado. Em outras palavras, para haver mudança de direção, é preciso que se aplique uma força em direção diferente à do movimento, segundo os pressupostos da Primeira Lei de Newton: "Todo corpo persevera em seu estado de repouso ou de movimento uniforme em linha reta, a menos que seja obrigado a mudar aquele estado por forças impressas nele" (tradução nossa) [53, p. 12]. Trata-se da lei da inércia, que evoluiu do conceito de impetus.

$\mathrm{Na}$ segunda demonstração, Azeredo Coutinho parte de outro fato conhecido, segundo o qual se a um corpo boiante levado pela correnteza de um fluido qualquer for dado um impulso, ou velocidade maior que a corrente do fluido, esse corpo formará no mesmo fluido duas correntes laterais na razão inversa da velocidade do corpo boiante impelido [26, p. 72]. A ideia então, a partir daí, seria colocar um corpo sólido de encontro a uma dessas correntes, a exemplo de um leme, de forma que lhe proporcionasse uma resistência. $\mathrm{O}$ corpo, encontrando resistência em um dos seus lados, o esquerdo, por exemplo, mudaria de direção sobre esse lado.

A segunda demonstração parte, portanto, de uma consequência imediata da primeira. No caso do ar, todo fluido vai se opor ao movimento de um corpo nele imerso, e essa força de oposição é chamada de resistência ou arrasto. A forma do corpo é um dos fatores que determinam tal resistência, porém Azeredo Coutinho não se preocupou com ela em sua proposta. No caso dos primeiros balões, dava-se preferência ao formato esférico e de grandes dimensões, para aumentar o empuxo e a estabilidade. Entretanto, essas características faziam com que o balão apresentasse grande resistência em sua passagem pelo ar. Tipicamente, os balões dirigíveis atuais apresentam um formato alongado. Foi o barão Scott que, dando solução similar à de J.B. Meusnier (1754-1793), baseou-se na forma dos peixes mais rápidos, propondo um formato adequado para o seu balão. A forma alongada dos peixes é uma adaptação natural que os permite nadar com maior mobilidade, em virtude da diminuição da resistência do fluido. A Figura 6 ilustra essas ideias.

Trata-se de uma ilustração de 1835 do Flying Dolphin, o projeto de um aeróstato com formato de peixe e impulsionado a remos, projetado pelo inventor suíço e armeiro Jean Samuel Pauly (1766-c.1821), sob o patrocínio de Durs Egg (1748-1831).

As asas e os remos eram muito menores que a superfície do balão e, dessa forma, o arrasto se tornou muito maior que a força motriz utilizada, a qual, nos casos apresentados, era a humana. A força muscular dos tripulantes era insignificante ante a força dos ventos [55-56]. Era preciso, então, aumentar a força de propulsão para vencer a resistência do meio. Essa é a semente das ideias dos propulsores que são utilizados nos dirigíveis e aviões da atualidade. A principal diferença entre um aeróstato não dirigível e um dirigível reside no fato de que este último é autopropulsionado. O balão não dirigível está totalmente à mercê do vento, enquanto o dirigível pode se mover na direção desejada, independentemente do vento.

A proposição de que se deve imprimir ao corpo boiante uma velocidade maior que a corrente do fluido nos conduz a um princípio relativamente intuitivo: a velocidade do dirigível deve ser maior que a velocidade do vento, caso contrário aquele ficará à mercê deste. Por conseguinte, existe uma relação entre a velocidade do balão e a velocidade do vento para que haja dirigibilidade. A ideia básica envolvida no processo é a que o inventor brasileiro Alberto Santos Dumont (1873-1932) usaria posteriormente para produzir seu balão dirigível: seria preciso impelir o balão a uma velocidade maior que a do vento, pois só assim se conseguiria avançar contra a vontade do meio [57]. Isso difere da navegação na água, onde um barco a vela é capaz até mesmo de navegar contra o vento, sem o auxílio de motores. Tudo é uma questão do posicionamento da vela. Esta, tendo um formato adequado, faz

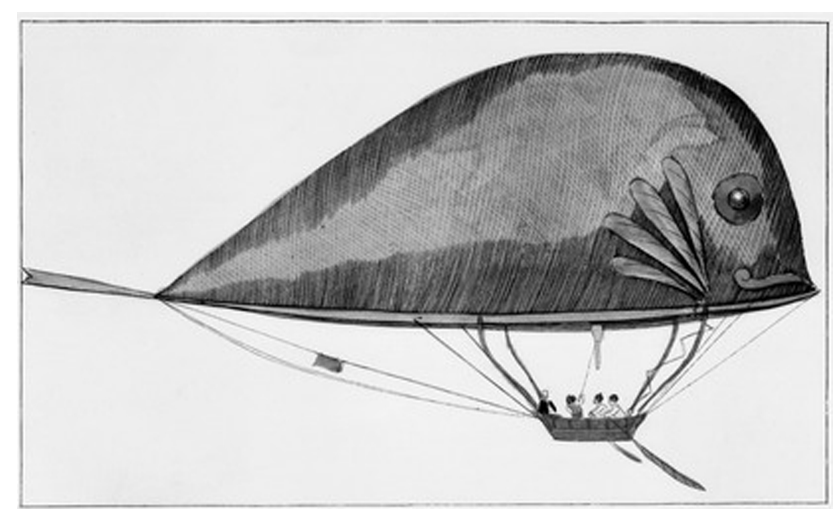

Figura 6: Flying Dolphin, balão movido a remos com formato de peixe. (Fonte: Science \& Society Picture Library Prints) 
com que a maior parte da força do vento contrário seja desviada 17 .

A necessidade de a velocidade do dirigível ser maior que a velocidade do vento pode ser demonstrada geometricamente pelo chamado teorema das velocidades [58-60]:

\section{É necessário munir o dirigível de um motor e de um propulsor capaz de lhe dar uma velocidade própria superior à do vento. Todo o sistema se tornará um verdadeiro navio ou um dirigível. (tradução nossa) [58, p. 70]}

Essa conclusão está, por conseguinte, condizente com as argumentações de Azeredo Coutinho, que no encadeamento lógico de seu raciocínio, procurou demonstrar como o desejado ponto de apoio poderia ser gerado para obter o direcionamento: o aumento da velocidade do balão. O que o autor descreve, com outras palavras, é o efeito de arrasto, ou seja, a oposição oferecida pelo fluido ao movimento de um corpo nele imerso. Essa oposição aumenta com a velocidade. No caso do ar - que tem uma resistência ínfima comparada à da água -, este pode ser considerado tênue quando em repouso. Deixa de sêlo, porém, à medida que a velocidade de propulsão de um corpo nele imerso aumenta, crescendo em proporção muito maior a resistência de avanço, a qual decorre do vento relativo - um vento contrário que surge quando um corpo se movimenta na atmosfera. Com esse aumento de resistência, é oferecido um ponto de apoio para que um leme possa atuar no ar da mesma forma que o faz na água. É a composição de forças que faltava para proporcionar uma mudança de direção no ar. A ação do leme é desviar o fluxo do vento relativo, criando dois fluxos de diferentes velocidades e, consequentemente, diferentes pressões nas partes dianteira e traseira desse aerofólio, de acordo com o princípio de Bernouille ${ }^{18}$ A diferença de pressão cria um par ação-reação, explicado pela Terceira Lei de Newton: "A ação é sempre igual e contrária à reação: quer dizer que as ações mútuas entre dois corpos são sempre iguais e em sentidos contrários" (tradução nossa) [53, p. 13].

Isso é o que permite rotacionar a nave em uma direção que depende da posição do leme. O mesmo princípio é aplicado às velas dos barcos e às asas dos aviões. Em suma, com suas palavras, Azeredo Coutinho expõe a mesma conclusão a que se chega com o teorema das velocidades: é preciso que a velocidade do balão seja superior à velocidade do vento para que haja dirigibilidade. Isso conduz à demonstração do segundo teorema: "Dar-se uma força impulsiva no balão de uma velocidade maior

\footnotetext{
17 Esta técnica é denominada "navegar à bolina" e é conseguida com uma navegação em zigue-zague ao redor do leito do vento. A técnica foi desenvolvida pelos portugueses nas caravelas do século $\mathrm{XV}$, a partir do uso de velas triangulares, as quais tinham origem árabe.

18 Princípio de Bernouille: se a velocidade de uma partícula de um fluido aumenta enquanto ela se escoa ao longo de uma linha de corrente, a pressão do fluido deve diminuir e vice-versa.
}

do que a da corrente do fluido da atmosfera sobre a qual o balão boia" [26, p. 73].

Para a demonstração do segundo teorema, Coutinho parte da constatação de que o ar é um corpo elástico e, sendo assim, ao ser comprimido por uma força qualquer, resiste à força de compressão por uma força igual de reação. $\mathrm{O}$ ar pode ser comprimido por máquinas artificiais e também é expelido por meio dessas máquinas, a exemplo de uma espingarda de vento, de um fole, ou por vapor da água quente, por pólvora inflamada etc. O impulso do ar comprimido sendo desenvolvido contra a atmosfera é por esta repelido por uma força igual de reação, como numa peça de artilharia que, ao mesmo tempo em que dispara contra a atmosfera, também é repelida. Assim, se o balão com sua barquinha for convertido em um sistema de corpo único e se a esse corpo for adicionada uma máquina impelente ou que dispare o ar desenvolvido contra a atmosfera, esta, pela sua força de reação, dará ao sistema um impulso de velocidade maior do que a da corrente do fluido sobre o qual o balão boia. Coutinho acrescenta não ser necessário que a força impelente esteja sempre atuante, bastando repeti-la a intervalos de tempo regulares. Esse raciocínio já é derivado do princípio da inércia embutido na Primeira Lei de Newton, e a ideia de força que o autor aqui usa é o atual conceito de impulso, ou seja, uma força atuante durante um intervalo de tempo, o qual equivale à variação da quantidade de movimento de um corpo.

Na ciência moderna, encontram-se novas concepções acerca das ideias de manutenção do movimento e de força. Ao longo da história, o conceito de força foi muito discutido. Para Aristóteles, força era algo que mantinha o corpo em movimento; dessa forma, o agente que a provocou deveria manter o contato direto com o corpo durante todo o tempo, representando um conceito que se adequava à visão de mundo do filósofo grego. O filósofo neoplatônico João Filoponos de Alexandria (c.490-c.570), com obras baseadas na física aristotélica, concordou com Aristóteles no sentido de que a força mantinha o movimento dos corpos, mas discordou da necessidade de ela requerer permanente contato com o corpo, visto que a força seria transferida ao corpo pelo agente que a causou. Ao se empurrar um objeto, então, ele manteria o movimento durante certo tempo.

As ideias de Filoponos serviram de referência à teoria do impetus de Jean Buridan no século XIV, segundo a qual a força aplicada a um corpo ficaria impregnada nele durante todo o seu movimento, abrangendo todo o movimento do Universo, incluído o movimento dos planetas. Já se tratava, portanto, da sugestão de uma física única, que explicasse tanto os movimentos terrestres quanto os movimentos celestes.

A união da mecânica terrestre com a mecânica celeste só veio a ocorrer, de forma efetiva e generalizada, com os trabalhos de Newton no século XVII. A partir desse momento, a mecânica clássica passou a ser baseada nas três Leis de Newton, segundo as quais o conceito de força 
passou a ser o de interação entre dois corpos. O conceito de inércia newtoniana já estava presente nos compêndios de Coimbra. Na Recreação Filosófica, de Teodoro de Almeida, vários conceitos modernos, como o de inércia e de quantidade de movimento, já eram abordados. $\mathrm{O}$ termo "força impulsiva" usado por Azeredo Coutinho já estava atrelado, portanto, a essas novas concepções, quando o bispo explica que não há necessidade de manter a força o tempo todo. Assim, o que Coutinho descreve para propulsionar seu balão, em linhas gerais, é a ação do empuxo - uma força de reação descrita quantitativamente pelas Segunda e Terceira Leis de Newton. É exatamente a ação de um propulsor: as pás do propulsor aceleram o ar em uma direção, enquanto o ar devolve uma força igual em módulo e direção, mas no sentido oposto. É o que se denomina empuxo aerodinâmico do propulsor, distinto do empuxo hidrostático de Arquimedes, que faz com que o balão ascenda.

A tecnologia disponível na época de Azeredo Coutinho, todavia, conduzia a uma série de limitações. O voo em balões progrediu muito pouco desde que foram inventados até o final do século XIX, e foi só nesse período que houve muitos experimentos para a consecução do voo controlado. Somente no início do século XX o problema da dirigibilidade foi efetivamente solucionado com o voo de Santos Dumont, em 1901, em torno da Torre Eiffel, a bordo de seu dirigível $n^{\circ} 6$. Com esse feito, Santos Dumont ganharia o Prêmio Deutsch [61-63]. Motores a vapor e motores elétricos movidos a bateria, não existentes no tempo de Azeredo Coutinho, foram acrescentados para permitir a propulsão que havia sido idealizada pelo bispo. Tais engenhos, entretanto, tornaram-se impraticáveis num primeiro momento, em razão do grande peso desses motores, sendo necessário grande volume de gás para erguê-los. Somente com o advento dos motores a explosão, movidos a gasolina, mais potentes e leves que os motores elétricos ou a vapor, é que o problema passou a ser resolvido. Com esse tipo de motor é que o alemão Friedrich Hermann Wölfert (1850-1897) voou no dirigível Deutschland, equipado com um motor Daimler de 8 cv, em 1896 e 1897. Porém, seu balão explodiu em pleno ar, no dia 12 de junho de 1897. Já o projeto de Santos Dumont, com motores a gasolina para dirigíveis, obteve sucesso.

\section{Considerações finais}

Neste artigo procuramos contribuir para a historiografia apresentando as ideias de um brasileiro pouco conhecido na história da física, até por pertencer a um período histórico que carece de maiores investigações nesse sentido: o período colonial. Além disso, o processo historiográfico tradicional tem características fortemente eurocêntricas, em razão do que a contribuição de intelectuais nascidos no que viria a ser a nação brasileira é pouco conhecida.

O manuscrito do bispo Azeredo Coutinho sobre o problema do voo dirigido de balões não é citado na história da aeronáutica, que contou com importantes participações de brasileiros. Trata-se de um documento que ainda não havia sido explorado em mais detalhes pela historiografia, e a análise de seu conteúdo exigiu a caracterização de toda uma conjuntura para entendimento apropriado, revelando importantes princípios físicos, cuja interpretação foi sendo amadurecida no decorrer da história.

Observamos, a partir da análise realizada, que Azeredo Coutinho se aproximou bastante dos requisitos necessários para dar dirigibilidade ao voo de um balão, usando princípios da física clássica newtoniana. Contudo, além de a tecnologia necessária para a implementação de suas ideias não estar disponível à época, Coutinho deixou de citar outros elementos fundamentais para atingir a dirigibilidade, como o formato do balão, por exemplo. Foi só no final do século XIX que a preocupação em reduzir o arrasto aerodinâmico e as propostas de alteração dos formatos dos dirigíveis conduziram aos fundamentos básicos para o desenvolvimento da aerodinâmica.

\section{Agradecimentos}

Agrademos às professoras Suzana Jorge G.A. Carvalho e Laura Carvalho M. Silva pelas revisões finais do texto e pelas sugestões.

\section{Referências}

[1] J.J.C.A. Coutinho, Ofício (2 ${ }^{a}$ via) do Bispo de Pernambuco ao Secretário de Estado da Marinha e Ultramar, Rodrigo de Sousa Coutinho, sobre as cerimônias de abertura dos estudos do Seminário da cidade de Olinda e o mapa dos alunos que frequentam as aulas no dito Seminário, disponível em https://bdlb.bn.gov.br/redeMemoria/ handle/123456789/187334.

[2] J.J.C.A. Coutinho, Estatutos do Seminário Episcopal de N. Senhora da Grasa da cidade de Olinda de Parnambuco, disponível em http://bdlb.bn.gov.br/acervo/handle/123456789/433785.

[3] G.L. Alves, O pensamento burguês e o plano de estudos no Seminário de Olinda: 1800-1836. Tese de Doutorado, Universidade Estadual de Campinas, Campinas (1991).

[4] G.L. Alves, O pensamento burguês no Seminário de Olinda: 1800-1836 (Autores Associados, Campinas, 2001).

[5] J.C.C. Andrades, O sertanejo filósofo e o filósofo dos sertôes: pressupostos do ensino das ciências naturais modernas no pensamento do bispo Azeredo Coutinho (1772-1836). Tese de Doutorado, Centro Federal de Educação Tecnológica, Rio de Janeiro (2018).

[6] E.B. Burns, American Historical Review 44, 145 (1964).

[7] E.B. Burns, in Conflito e continuidade na sociedade brasileira - ensaios, editado por H.H. Keith and S.F. Edwards (Civilização Brasileira, Rio de Janeiro, 1970), p. 123.

[8] E.B. Burns, A history of Brasil (Columbia University Press, New York, 1980), p. 121.

[9] N.M. Cantarino, A razão e a Ordem: O bispo José Joaquim da Cunha de Azeredo Coutinho e a defesa ilustrada 
do Antigo Regime Português (1742-1821). Tese de Doutorado, Universidade de São Paulo, São Paulo (2012).

[10] E.M. Cardoso, Tendências renovadoras e conservadoras na filosofia da educação de José Joaquim da Cunha de Azeredo Coutinho. Dissertação de Mestrado, Pontifícia Universidade Católica do Rio de Janeiro, Rio de Janeiro (1975).

[11] E.M. Cardoso, in Pombal e a cultura brasileira, editado por A. Paim (Fundação Cultural Brasil-Portugal, Rio de Janeiro, 1982), p. 50.

[12] M.L.V. Lyra, A utopia do poderoso império: Portugal e Brasil: bastidores da política, 1798-1822 (Sette Letras, Rio de Janeiro, 1994), p. 88.

[13] G.P.C.P. Neves, O Seminário de Olinda: educação, cultura e política nos tempos modernos. Dissertação de Mestrado, Universidade Federal Fluminense, Niterói (1984).

[14] A.J. Siqueira, Os padres e a teologia da ilustração: Pernambuco 1817 (Universidade Federal de Pernambuco, Recife, 2009), p. 144.

[15] S.A. Siqueira, Revista de História 28, 141 (1964).

[16] S.A. Siqueira, A Ilustração no Brasil: Azeredo Coutinho e o Seminário de Olinda (Instituto de Estudos Brasileiros da Universidade de Taubaté, Taubaté, 1978).

[17] N.L.B. Sucupira, in História da cultura brasileira, editado por M.B.P. Diégues Jr (FENAME/CFC, Rio de Janeiro, 1973), v. 2, p. 356.

[18] G.M.W. Verri, in Memorat: memória e cultura escrita na formação brasileira, editado por G.M.W. Verri (Universidade Federal de Pernambuco, Recife, 2010), p. 53.

[19] D.A.V. Tonidandel, A.E.A. Araújo e W.C. Boaventura, Rev. Bras. Ens. Fis. 40, 4602 (2018).

[20] J.P.M. Chaib e M.C. Aguiar, Cad. Bras. Ens. Fís. 33, 142 (2016).

[21] L.C. Gomes, Cad. Bras. Ens. Fís. 29, 1030 (2012).

[22] R.A. Martins, Rev. Bras. Ens. Fis. 39, 1601 (2017).

[23] PORTUGAL, Informaçoens de geração, vida e costumes de Joze Joaquim da Cunha Azeredo Cout. ${ }^{\circ}$ (Arquivo Nacional da Torre do Tombo, Lisboa, 1785).

[24] F. Morais, in Anais da Biblioteca Nacional do Rio de Janeiro, editado por R. Garcia (Biblioteca Nacional, Rio de Janeiro, 1940), v. 62, p. 136.

[25] Universidade de Coimbra, Estatutos da Universidade de Coimbra (Regia Officina Typografica, Lisboa, 1772), Livro III, p. 5.

[26] J.J.C.A. Coutinho, in Collecção de alguns manuscriptos curiosos do Ex ${ }^{m o}$. Bispo d'Elvas, editado por L. Thompson (L. Thompson, Londres, 1819), p. 71.

[27] C. Dollfus e H. Bouché, Histoire de L'Aéronautique (L'Illustration, Paris, 1938), p. 11.

[28] N.J.T.M Needham, Science and civilization in china (University Press, Cambridge, 1965), v. 4, p. 596.

[29] R.M. Visoni e J.B.G. Canalle, Rev. Bras. Ens. Fis. 31, 3604 (2009).

[30] F.F.C. Figueiredo, in Historia e memorias da Academia Real das Sciencias de Lisboa (Typografia da Academia Real das Sciencias de Lisboa, Lisboa, 1843), $2^{\mathrm{a}}$ serie, Tomo I, parte I, p. 133-155.

[31] Relação da experiência aerostática feita em Coimbra, Gazeta de Lisboa, Lisboa, 17 de julho de 1784, disponível em: http://hemerotecadigital.cm-lisboa.pt/ Periodicos/GazetadeLisboa/GazetadeLisboa.htm
[32] A.K.T. Assis, Revista Brasileira de História da Ciência, 16, 69 (1996).

[33] M.A. Braga, A. Guerra e J.C. Reis, Breve história da ciência moderna (Zahar, Rio de Janeiro, 2011), v. 3, p. 20.

[34] J.M.M.H. Thijssen, in New Dictionary of Scientific Biography, editado por N. Koertge (Charles Scribner's Sons, New York, 2007), v. 1, p. 34.

[35] J. Wilkins, Le monde dans la lune (Chez Jaques Cailloüe, Rouen, 1655), p. 247.

[36] A.G. Rozier, Dissertation sur les aérostates desanciens et des modernes (Chez les libraires des nouveautés, Geneve, 1784), p. 43.

[37] D. Bourgeois, Recherches sur l'art de voler, depuis la plus haute Antiquité jusqu'à ce jour (Chez Cuchez, Paris, 1784), p. 43.

[38] J. Leslie, Treatises on various subjects of natural and chemical philosophy (Adam and Charles Black, Edinburgh, 1838), p. 118.

[39] R.M. Ballantyne, Up in the clouds (James Nisbet, London, 1869), p. 19.

[40] H. Graffigny, Les ballons dirigeables et la navigation aérienne. (J-B Baillière et fils, Paris, 1902), p. 17.

[41] J. Duhem, Histoire des idées aéronautiques avant Montgolfier (Sorlot, Paris, 1943), p. 334.

[42] L. Angioni, Aristóteles: Física I-II (UNICAMP, Campinas, 2009).

[43] R.R. Bombini, Alberto da Saxônia e a argumentação por dez orbes celestes no século XIV. Dissertação de Mestrado, Pontifícia Universidade Católica de São Paulo, São Paulo (2016).

[44] J.M.M.H. Thijssen, Vivarium, 42, 18 (2004).

[45] A. Saxonia e B. Patar, Expositio et quaestiones in Aristotelis Physicam ad Albertum de Saxonia attributae: Édition critique, Tome I - Introduction (Peeters, Paris, 1999).

[46] A. Saxonia e B. Patar, Expositio et quaestiones in Aristotelis Physicam ad Albertum de Saxonia attributae: Édition critique, Tome III - Quaestiones (L. IV-L.VIII) (Peeters, Paris, 1999), p. 655.

[47] E.W.J.W. Mach, The science of mechanics: a critical and historical account of its development (The Open Court Publishing Company, Chicago, 1919), p. 112.

[48] T. Almeida, Recreação filosofica ou Dialogo sobre a filosofia natural para instrucção de pessoas curiosas, que não frequentarão as aulas (Regia Officina Typographica, Lisboa, 1786).

[49] F. Marion, Wonderful ballon ascents or The conquest of the skies: A history of ballons and balloon voyages (Cassell, Petter \& Galpin, London, 1888).

[50] H.L. Barros, Desafio de voar: brasileiros e conquista do ar, 1709-1914 (Metalivros, São Paulo, 2006).

[51] L.T. White, Medieval technology and social change (Oxford University Press, Oxford, 1962), p. 134.

[52] N.C.T. Milly, in Première suite de la description des expériences aérostatiques de MM. Montgolfier, et de celles auxquelles cette découverte a donné lieu, editado por L'Académie Royale des Sciences (Cuchez, Paris, 1784), Tomo 2, p. 315-339.

[53] I. Newton, Philosophiae naturalis principia mathematica (Amstaelodami Sumptibus Societatis, [S.1.], 1714). 
[54] R.S. Alonso, in Teoría de la educación, metodología y focalizaciones: la mirada pedagógica, editado por J.M. López e T.R.S. Alonso (Netbiblo, La Coruña, 2012), p. 50.

[55] E.A. Bizerra, Santos Dumont e o desenvolvimento da dirigibilidade dos balões. Dissertação de Mestrado, Pontifícia Universidade Católica de São Paulo, São Paulo (2008).

[56] F.A. Castrioto, Experiências aerostáticas, Gazeta de Lisboa 1784: memória sobre a máquina aerostática de Félix António Castrioto (Dantes, Rio de Janeiro, 2008), p. 11.

[57] H.L. Barros, Santos Dumont (Index, Rio de Janeiro, 1986), p. 37.

[58] H. André, Les dirigeables: étude complète de la direction des ballons, des tentatives reéalisées et des projets nouveaux (Librarie Polyt. Ch. Béranger, Paris,1902), p. 66.

[59] R. Soreau, Le problème de la direction des ballons (Centrale des Sciences, Paris, 1893), p. 6.

[60] L.S. Forge, La conquête de l'air: le probleme de la locomotion aeriénne; les dirigeables et l'aviation - leurs applications (Berger-Levraut \& Cie, Paris, 1907), p. 56.

[61] A.S. Dumont, McClures Magazine 19, 462 (1902).

[62] A.S. Dumont, Dans l'air (Librairie Charpentier et Fasquelle, Paris, 1904).

[63] A.S. Dumont, O que eu vi, o que nós veremos (Hedra, São Paulo, 1918). 